\title{
L-Thyroxine Treatment of Patients with Subclinical Hypothyroidism Reduce Inflammation
}

\author{
Orhan Kursat Poyrazoglu ${ }^{1}$, Yusuf Ozkan ${ }^{*}, 2$, Mehmet Ozden ${ }^{3}$, Ramis Colak ${ }^{2}$, Goksel Ozalp ${ }^{1}$ and \\ Emir Dönder ${ }^{1}$
}

\author{
${ }^{1}$ Firat University Faculty of Medicine Department of Internal Medicine, ${ }^{2}$ Department of Endocrinology, ${ }^{3}$ Department of \\ Immunology, Elazig, Turkey
}

\begin{abstract}
Background: Subclinical hypothyroidism (SCH) has been found to be associated with cardiovascular disease including atherosclerosis which is also called inflammatory disorder. The objective of this study was, to investigate the efficacy of L-thyroxine therapy on inflammation in patients with SCH and to determine whether treatment of SCH would reduce inflammation.

Methods: Twenty patients with thyroid stimulating hormone levels between 5 and $10 \mathrm{mU} / \mathrm{L}$ and twenty healthy persons (control) were enrolled to the study. $0.025-0.075 \mathrm{mg} / \mathrm{d}$ L-thyroxine therapy was given to the patients. Patients were followed till they became euthyroid. C-reactive protein (CRP), lipid profile and thyroid function tests were evaluated. CRP was determined by a high sensitivity immunoassay.
\end{abstract}

Results: CRP, total cholesterol and low-density lipoprotein (LDL) were significantly elevated in patients with subclinical hypothyroidism compared to the control group at baseline ( $<<0.01, p<0.05, p<0.001$, respectively). L-thyroxine therapy significantly decreased CRP $(\mathrm{p}<0.01)$ and low-density lipoprotein in treatment group $(\mathrm{p}<0.05)$. Nevertheless, no significant change was found in other lipid parameters.

Conclusion: These findings demonstrate that patients with $\mathrm{SCH}$ are characterized by inflammatory disorders and higher lipid profile.

Keywords: Subclinical hypothyroidism, atherosclerosis, inflammation, C-reactive protein.

\section{INTRODUCTION}

Cardiovascular diseases are recognized as a leading cause of morbidity and mortality in general population [1]. Although the reasons behind the development of cardiovascular diseases are multifactorial, atherosclerosis plays a prominent role. Traditional risk factors such as hypertension, diabetes mellitus, altered lipid profile and nontraditional risk factors such as oxidative stress, inflammation and homocysteinemia, have been shown to be associated with atherosclerotic cardiovascular disease [2-5]. Over the last years; much attention has been paid to the idea that inflammation plays a key role in atherosclerosis. C-reactive protein (CRP) is a sensitive and objective marker of inflammation and may act in the pathogenesis of atherosclerosis via several mechanisms [6, 7]. Pasceri et al. [8] proposed that CRP directly stimulates the inflammatory reaction of arteriosclerosis by inducing the expression of adhesion molecule in vascular endothelial cells and further hypothesized that CRP could be a treatment target for arteriosclerosis. Furthermore, elevated levels of CRP have been directly related to the risk of cardiovascular disease such as myocardial infarction [9-12].

Subclinical hypothyroidism (SCH) is a metabolic condition characterized by elevations in thyroid-stimulating

*Address correspondence to this author at the Firat University Faculty of Medicine, Frrat Medical Center Department of Endocrinology, 23200Elazığ, Turkey; E-mail: dryusufozkan@hotmail.com hormone (TSH) level with normal free $\mathrm{T}_{4}\left(\mathrm{fT}_{4}\right)$ and normal free $\mathrm{T}_{3}\left(\mathrm{fT}_{3}\right)$ [13]. The most common cause of $\mathrm{SCH}$ in the community is chronic autoimmune thyroiditis [14]. In addition, the reported prevalence of $\mathrm{SCH}$ ranges from $1 \%$ to $10 \%$ in the general population [15-17]. On the other hand, $\mathrm{SCH}$ have also been found to be associated with cardiovascular disease due to atherosclerosis. However, the idea that $\mathrm{SCH}$ and thyroid autoimmunity are also risk factors for cardiovascular disease is still controversial [18-21]. Besides, several studies have been published that L-tyroxine treatment of SCH not only causes various effect upon lipid parameters and inflammation but also arrhythmias particularly in elderly patients [22-24].

The aim of this study was to investigate the effect of Lthyroxine therapy on inflammation in patients with $\mathrm{SCH}$ and to determine whether treatment of $\mathrm{SCH}$ would lessen inflammation.

\section{MATERIALS AND METHODS}

\section{Study Protocol}

After written informed consent was obtained from all participants, patients who were admitted to endocrinology polyclinic were registered to the study consecutively. Twenty patients with TSH levels between 5 and $10 \mathrm{mU} / \mathrm{L}$ with normal $\mathrm{fT}_{4}$ and normal $\mathrm{fT}_{3}$ levels ( $\mathrm{SCH}$ group) and age and sex matched twenty healthy persons with normal serum $\mathrm{TSH}, \mathrm{fT}_{4}$ and $\mathrm{fT}_{3}$ levels (control group) were enrolled to the study. Patients with SCH were divided into 2 subgroups according to 
their autoimmune markers as well. After an overnight fasting period, all patients underwent full medical assessment and laboratory examinations to rule out the non-thyroidal illness. Patients receiving amiodarone, lithium, anti-thyroid therapy, anti-oxidant and anti-inflammatory drugs, and other potential causes of elevated CRP such as patients with chronic diseases including cardiovascular disease, diabetes mellitus, tobacco habit, periodontal disease and infection were excluded. Patients who had previous history of thyroid disease were also excluded. $0.025 \mathrm{mg} / \mathrm{d} \mathrm{L}$-thyroxine therapy was given to the patients with subclinical hypothyroidism. L-thyroxine therapy dose was titrated for patients individually according to their thyrotropine levels. Patients were followed twice a week until they became euthyroid. We did not observe any side effects during the trial.

\section{Laboratory Analyses}

Blood samples were drawn before treatment and when patients were euthyroid. The investigators who did the laboratory analyses were blinded either each group. Samples were centrifuged and frozen at $-30^{\circ} \mathrm{C}$ until they were studied. High sensitivity CRP (hs CRP), lipid profile (Total cholesterol (TC), high density lipoprotein (HDL), low density lipoprotein (LDL) and triglyceride (TG), thyroid function tests (TSH, free $\mathrm{T}_{3}$, and free $\mathrm{T}_{4}$ ) and anti-thyroglobulin antibodies (anti-TG), anti-microsomal antibodies (anti-M) were evaluated. hs CRP were determined with nefelometric test (Dade Behring, Marburg GmbH, Germany) by using BN 100 machine (Dade Behring, Liederbach, Germany). Normal range of hs CRP is 0-2 $\mathrm{mg} / \mathrm{l}$. The thyroid function tests were measured using one of the luminescence immunoassay methods known as the electrochemiluminescence immunoassay (ECLIA) method. For measurements of fT3, fT4 and TSH, Elecsys fT3 reagent kit11731386, Elecsys FT4 reagent kit-11731297, Elecsys TSH reagent kit-11731459, and Roche's Elecsys 1010/1010 kit were used, respectively. A Roche modular analytics E170 (Elecsys module) immunoassay analyzer that is compatible with these kits was used for the thyroid function tests. Serum levels of antiTG and anti-M were measured with ELISA kits (Trinity Biotech Plc, Co Wicklow, Ireland.) by using full automatic Triturus (Grifols Diagnostic, Barcelona, Spain) micro ELISA device. Serum levels of lipids were measured by AU600 autoanalyzer (Olympus Optical Co., Japan).

\section{Statistical Analyses}

Statistical analysis was performed using SPSS 10.0. Data were presented as mean \pm SEM. Data were normally distributed. To compare values obtained before and after Lthyroxine therapy, paired - $t$ test was used. On the other hand, unpaired $\mathrm{t}$ - test was used to examine the difference between SCH and control group. Differences between SCH subgroups were also evaluated with unpaired $\mathrm{t}$ - test.

\section{RESULTS}

The main characteristics of patients are summarized in Table 1. There were no significant differences in any clinical parameters (age, gender, BMI) between patients with $\mathrm{SCH}$ and control group. Anti-TG and anti-M were all negative in control group. When we compare lipid parameters, only serum LDL and TC levels were significantly higher in SCH group than control group and there were no significant changes in other lipid parameters. Additionally, TSH and hs
CRP values were also significantly elevated in patients with $\mathrm{SCH}$ in comparison to control group (Table 2).

Table 1. Main Characteristics of SCH and Control Group

\begin{tabular}{|l|c|c|c|}
\hline & Control $(\mathbf{n}=\mathbf{2 0})$ & SCH Group $(\mathbf{n}=\mathbf{2 0})$ & P \\
\hline \hline Age $(\mathbf{y e a r})$ & $36.2 \pm 2.3$ & $37.5 \pm 3$ & NS \\
\hline Sex $(\mathbf{m} / \mathbf{f})$ & $1 / 19$ & $1 / 19$ & NS \\
\hline Height $(\mathbf{c m})$ & $156.7 \pm 1.8$ & $158.7 \pm 1.4$ & NS \\
\hline Weight $(\mathbf{k g})$ & $67.4 \pm 3$ & $73.4 \pm 2.9$ & NS \\
\hline BMI $\left(\mathbf{k g} / \mathbf{m}^{\mathbf{2}}\right)$ & $27.4 \pm 1.1$ & $29.3 \pm 1.2$ & NS \\
\hline Anti-M $(\%)$ & - & 60 & - \\
\hline Anti-TG $(\%)$ & - & 55 & - \\
\hline
\end{tabular}

BMI: Body Mass Index Anti-M: Anti microsomal anticor, Anti-TG: Anti thyroid thyroglobuline anticor,

Table 2. Baseline Laboratory Values of SCH and Control Group

\begin{tabular}{|l|c|c|c|}
\hline & Control (n= 20) & SCH Group $(\mathbf{n}=\mathbf{2 0})$ & P \\
\hline \hline TC (mg/dl) & $171.9 \pm 6.4$ & $208.3 \pm 12.3$ & $<\mathbf{0 . 0 5}$ \\
\hline HDL (mg/dl) & $39.4 \pm 1.9$ & $41.9 \pm 1.6$ & NS \\
\hline LDL (mg/dl) & $106.7 \pm 5.1$ & $146.4 \pm 8.4$ & $<\mathbf{0 . 0 0 1}$ \\
\hline TG (mg/dl) & $124.8 \pm 11.8$ & $190.3 \pm 25.6$ & NS \\
\hline hs CRP (mg/l) & $1.8 \pm 0.2$ & $4 \pm 0.7$ & $<\mathbf{0 . 0 1}$ \\
\hline TSH (mU/l ) & $1.9 \pm 0.3$ & $6.7 \pm 0.3$ & $<\mathbf{0 . 0 0 1}$ \\
\hline
\end{tabular}

TC: Total cholesterol, HDL: High density lipoprotein, LDL: Low density lipoprotein, TG: Triglyceride, hs CRP: high sensitivity C-reactive protein, TSH: Thyroid stimulant hormone.

In patients receiving L-thyroxine therapy, LDL, hs CRP, TSH serum levels, and BMI were significantly decreased after L-thyroxine therapy. On the other hand, TC, HDL and TG showed no significant changes (Table 3). No side effect was observed in any patient during L-thyroxine therapy.

Table 3. Laboratory Values of Patients with SCH (Before and After Treatment)

\begin{tabular}{|c|c|c|c|}
\hline & Before & After & $\mathbf{P}$ \\
\hline TC (mg/dl) & $208.3 \pm 12.3$ & $192.7 \pm 9.5$ & $>0.05$ \\
\hline HDL (mg/dl) & $41.9 \pm 1.6$ & $42.7 \pm 2.1$ & $>0.05$ \\
\hline LDL (mg/dl) & $146.4 \pm 8.4$ & $124.2 \pm 9.7$ & $<0.05$ \\
\hline TG (mg/dl) & $190.3 \pm 25.6$ & $141.7 \pm 20.7$ & $>0.05$ \\
\hline hs CRP (mg/l) & $4 \pm 0.7$ & $2.9 \pm 0.5$ & $<0.01$ \\
\hline TSH (mU/l ) & $6.7 \pm 0.3$ & $2.5 \pm 0.3$ & $<0.001$ \\
\hline $\mathrm{fT}_{3}(\mathrm{mU} / \mathrm{l})$ & $2.6 \pm 0.1$ & $3.2 \pm 0.1$ & $<0.001$ \\
\hline $\mathrm{fT}_{4}(\mathrm{mU} / \mathrm{l})$ & $1.1 \pm 0.04$ & $1.4 \pm 0.06$ & $<0.001$ \\
\hline Weight (kg) & $73.4 \pm 2.9$ & $72.6 \pm 2.9$ & $<0.05$ \\
\hline BMI $\left(\mathrm{kg} / \mathrm{m}^{2}\right)$ & $29.3 \pm 1.2$ & $28.9 \pm 1.3$ & $<0.05$ \\
\hline
\end{tabular}

TC: Total cholesterol, HDL: High density lipoprotein, LDL: Low density lipoprotein, TG: Triglyceride, hs CRP: high sensitivity C-reactive protein, TSH: Thyroid stimulant hormone, $\mathrm{fT}_{3}$ : free $\mathrm{T}_{3}, \mathrm{fT}_{4}$ : free $\mathrm{T}_{4}$, BMI: Body Mass Index 
CRP values of patients with negative autoimmune markers were higher than patients with positive autoimmune markers and control group. There was no significant difference in CRP serum levels between each subgroup of $\mathrm{SCH}$, but serum CRP levels of each group were significantly higher than control group. CRP serum levels of each $\mathrm{SCH}$ subgroup reduced significantly after treatment (Table 4).

Table 4. CRP Values of SCH Subgroups (Before and After Treatment) and Control Group

\begin{tabular}{|l|c|c|c|}
\hline & $\begin{array}{c}\text { CRP }(\mathbf{m g} / \mathbf{l}) \\
\text { Before }\end{array}$ & $\begin{array}{c}\text { CRP }(\mathbf{m g} / \mathbf{l}) \\
\text { After }\end{array}$ & p \\
\hline \hline SCH subgroup 1 $(\mathbf{n}=\mathbf{1 4})$ & $3.8 \pm 0.7^{* \dagger}$ & $2.8 \pm 0.5$ & $<0.05$ \\
\hline SCH subgroup 2 $(\mathbf{n}=\mathbf{6})$ & $4.4 \pm 1.4^{\dagger}$ & $2.9 \pm 1.2$ & $<0.05$ \\
\hline Control & $1.8 \pm 0.2$ & - & \\
\hline
\end{tabular}
$(+)$, SCH subgroup 2: anti-TG/M (-), ${ }^{*} \mathrm{p}>0.05$ (I $v s$ II) and ${ }^{\dagger} \mathrm{p}<0.05$ (I $v s$ control, II $v s$ control).

\section{DISCUSSION}

Hypothyroidism is closely associated with cardiac abnormalities. Patients with elevated serum thyrotropine levels and normal free $\mathrm{T}_{4}$ and normal $\mathrm{T}_{3}$, termed $\mathrm{SCH}$, may progress to permanent hypothyroidism. In addition, patients with $\mathrm{SCH}$ have more cardiovascular risk factors compared to the normal healthy population and are more likely to develop atherosclerosis and other cardiovascular diseases [25, 26]. Although hypothyroidism is usually associated with higher lipid profile, SCH has a diverse serum lipid profile. Significant elevation of lipid profile in $\mathrm{SCH}$ has been reported in some studies [27, 28], but other studies have not supported this results [29, 30]. In the present study, we found significant increases in total cholesterol and low-density lipoprotein cholesterol in patients with $\mathrm{SCH}$ before the thyroid hormone supplementation compared with euthyroid controls.

Recent data suggest that inflammation may play a central role in the background and complications of cardiovascular disease, particularly contribute to the development of atherosclerosis [6]. CRP known as a marker of inflammatory state is an independent risk factor for cardiovascular disease. In addition, a recently published report suggested that CRP is more than a marker and may be a mediator of atherosclerosis $[7,31]$. In fact, CRP may play a role in the pathogenesis of atherosclerosis through binding to damaged cells and activating complement system, displaying calciumdependent in vitro binding and aggregation of low density lipoprotein (LDL) and very LDL $[32,33]$. In our study, CRP values were significantly elevated in patients with $\mathrm{SCH}$ than euthyroid controls.

Although CRP level was found as a stronger predictor than the LDL-C level for myocardial infarction, ischemic stroke, coronary revasculature, or death due to cardiovascular causes in healthy women [34], some evidence suggest that lipid lowering models of therapy also reduce inflammation, which may reduce the risk of cardiovascular events, even for individuals with LDL-C levels in the normal range [35]. Nevertheless, because CRP and LDL-C levels appeared to identify somewhat different risk groups, the combined risk assessment was superior to that of either marker alone. In our study, serum levels of CRP and LDL-C reduced significantly after patients became euthyroid with Lthyroxine therapy. The reduction in LDL and CRP serum levels lead us to consider that treatment with L-thyroxine therapy may protect patients from cardiovascular morbidity and mortality due to atherosclerosis.

On the other hand, obese patients are associated with elevated inflammatory cytokines [36]. Additionally, it has been shown that serum levels of CRP and other inflammatory markers were positively correlated with BMI in overweight patients [37]. The study population of the current study was overweight. Although, we did not evaluate the effect of treatment of $\mathrm{SCH}$ upon weight of the participants, it is reasonable to expect a weight reduction in $\mathrm{SCH}$ patients through a favorable effect of L-thyroxine upon metabolism. This effect subsequently may contribute to a decrease in inflammation as reported above. Moreover, when we compared the CRP serum levels of patients with positive and negative autoimmune markers, we did not observe significant difference in each group. Although the numbers of patients and follow up were insufficient to evaluate this condition, it can be speculated that $\mathrm{SCH}$ patients even with negative thyroid autoimmune markers might have inflammatory disorder.

In conclusion, these findings indicate that patients with subclinical hypothyroidism have increased levels of LDL, TC and signs of low-grade inflammation (raised hs CRP levels) and that subclinical hypothyroidism might be a risk factor for development of cardiovascular disease. Besides, although further comprehensive studies are required to explain the relationship between $\mathrm{SCH}$ and cardiovascular diseases.

\section{REFERENCES}

[1] Pearson TA, Blair SN, Daniels SR, et al. AHA Guidelines for Primary Prevention of Cardiovascular Disease and Stroke: 2002 Update: Consensus Panel Guide to Comprehensive Risk Reduction for Adult Patients without Coronary or Other Atherosclerotic Vascular Diseases. American Heart Association Science Advisory and Coordinating Committee. Circulation 2002; 106: 388-91.

[2] Meng CQ. Inflammation in atherosclerosis: new opportunities for drug discovery. Mini Rev Med Chem 2005; 5: 33-40.

[3] Nesto R. C-reactive protein, its role in inflammation, Type 2 diabetes and cardiovascular disease, and the effects of insulinsensitizing treatment with thiazolidinediones. Diabet Med 2004; 21: $810-17$.

[4] Jialal I, Devaraj S, Venugopal SK. C-reactive protein: risk marker or mediator in atherothrombosis? Hypertension 2004; 44: 6-11.

[5] Gonzalez MA, Selwyn AP. Endothelial function, inflammation, and prognosis in cardiovascular disease. Am J Med 2003; 115: 99S-106.

[6] Ross R. Atherosclerosis: An inflammatory disease. N Engl J Med 1999; 340: 115-26.

[7] Libby P, Ridker PM. Inflammation and Atherosclerosis: Role of Creactive protein in Risk Assessment. Am J Med 2004; 116: 9S-16.

[8] Pasceri J, Willerson JT, Yeh ET. Direct proinflammatory effect of C-reactive protein on human endothelial cells. Circulation 2000; 102: $2165-8$

[9] Surks MI, Ortiz E, Daniels GH, et al. Subclinical thyroid disease: scientific review and guidelines for diagnosis and management. JAMA 2004; 291: 228-38.

[10] Abdelmouttaleb I, Danchin N, Ilardo C, et al. C-Reactive protein and coronary artery disease: additional evidence of the implication of an inflammatory process in acute coronary syndromes. Am Heart J 1999; 137: 346-51. 
[11] Ridker PM, Glynn RJ, Hennekens CH. C-reactive protein adds to the predictive value of total and HDL cholesterol in determining risk of first myocardial infarction. Circulation 1998; 97: 2007-11.

[12] Ridker PM, Rifai N, Rose L, Buring JE, Cook NR. Comparison of $\mathrm{C}$-reactive protein and low-density lipoprotein cholesterol levels in the prediction of first cardiovascular events. N Engl J Med 2002; 347: 1557-65.

[13] Ito M, Takamatsu J, Sasaki I, et al. Disturbed metabolism of remnant lipoproteins in patients with subclinical hypothyroidism. Am J Med 2004; 117: 696-9.

[14] Tunbridge WM, Vanderpump MP. Population screening for autoimmune thyroid disease. Endocrinol Metab Clin North Am 2000; 29: 239-54.

[15] Tunbridge WM, Evered DC, Hall R, et al. The spectrum of thyroid disease in a community: the Whickham survey. Clin Endocrinol 1977; 7: 481-93.

[16] Canaris GJ, Manowitz NR, Mayor G, Ridgway EC. The Colorado thyroid disease prevalence study. Arch Intern Med 2000; 160: 52634.

[17] Rivolta G, Cerutti R, Colombo R, et al. Prevalence of subclinical hypothyroidism in a population living in the Milan metropolitan area. J Endocrinol Invest 1999; 22: 693-7.

[18] Chu JW, Crapo LM. Should mild subclinical hypothyroidism be treated? Am J Med 2002; 112: 422- 3.

[19] Owen PJ, Lazarus JH. Subclinical Hypothyroidism: the case for treatment. Trends Endocrinol Metab 2003; 14: 257-61.

[20] Vanderpump M. Subclinical Hypothyroidism: the case against treatment. Trends Endocrinol Metab 2003; 14: 262-6

[21] Wells BJ, Hueston WJ. Are thyroid peroxidase antibodies associated with cardiovascular disease risk in patients with subclinical hypothyroidism? Clin Endocrinol (Oxf) 2005; 62: 5804.

[22] Caraccio N, Ferrannini E, Monzani F. Lipoprotein profile in subclinical hypothyroidism: response to levothyroxine replacement, a randomized placebo-controlled study. J Clin Endocrinol Metab 2002; 87: 1533-8.

[23] Serter R, Demirbas B, Korukluoglu B, Culha C, Cakal E, Aral Y. The effect of L-thyroxine replacement therapy on lipid based cardiovascular risk in subclinical hypothyroidism. J Endocrinol Invest 2004; 27: 897-903.

[24] Kvetny J, Heldgaard PE, Bladbjerg EM, Gram J. Subclinical hypothyroidism is associated with a low-grade inflammation, increased triglyceride levels and predicts cardiovascular disease in males below 50 years. Clin Endocrinol (Oxf) 2004; 61: 232-8.

[25] Fadeyev VV, Sytch J, Kalashnikov V, Rojtman A, Syrkin A, Melnichenko G. Levothyroxine replacement therapy in patients with subclinical hypothyroidism and coronary artery disease. Endocr Pract 2006; 12: 5-17.

[26] Staub JJ, Althaus BU, Engler H, et al. Spectrum of subclinical and overt hypothyroidism: effect on thyrotropin, prolactin, and thyroid reserve, and metabolic impact on peripheral target tissues. Am J Med 1992; 92: 631-42.

[27] Franklyn JA, Daykin J, Betteridge J, et al. Thyroxine replacement therapy and circulating lipid concentrations. Clin Endocrinol 1993; 38: 453-9.

[28] Dean J, Fowler P. Exaggerated responsiveness to thyrotropine releasing hormone: a risk factor in women with coronary artery disease. Br Med J 1985; 290: 1555-61.

[29] Lithell H, Boberg J, Hellsing K, et al. Serum lipoprotein and apolipoprotein concentrations and tissue lipoprotein-lipase activity in overt and SCH: the effect of substitution therapy. Eur J Clin Invest 1981; 11: 3-10.

[30] Bogner U, Arntz HR, Peters H, Schleusener H. Subclinical hypothyroidism and hyperlipoproteinaemia: indiscriminate Lthyroxine treatment not justified. Acta Endocrinol 1993; 128: 2026.

[31] Khreiss T, J-zsef L, Potempa LA, Filep JG. Conformational rearrangement in $\mathrm{C}$ reactive protein is required for pro inflammatory action on human endothelial cells. Circulation 2004; 109: 2016-22.

[32] Griselli M, Herbert J, Hutchinson WL, et al. C-reactive protein and complement are important mediators of tissue damage in acute myocardial infarction. J Exp Med 1999; 190: 1733-40.

[33] Pepys MB, Rowe IF, Baltz ML. C-reactive protein: Binding to lipids and lipoproteins. Int Rev Exp Pathol 1985; 27: 83-111.

[34] Ridker PM, Rifai N, Rose LL, Buring JE, Cook NR. Comparison of $\mathrm{C}$ - reactive protein and low-density lipprotein cholesterol levels in the prediction of first cardiovascular events. N Engl J Med 2002; 347: 1557-65.

[35] National Cholesterol Education Program. National Heart, Lung, and blood Institute. National Institute of Health. September 2002; NIH Publication No. 02-5215. http://www.nhlbi.nih.gov/guidelines/ cholesterol/atp3full.pdf

[36] Khaodhiar L, Ling PR, Blackburn GL, Bistrian BR. Serum levels of interleukin- 6 and C-reactive protein correlate with body mass index across the broad range of obesity. J Parenter Enteral Nutr 2004; 28: 410-5.

[37] Warnberg J, Morena LA, Measan MI, Marcos A; AVENA group. Inflammatory mediators in overweight and obese Spanish adolescents. The AVENA Study. Int J Obes Realt Metab Disord 2004; 28: 59-63. 